\title{
KINERJA STRUKTUR BANGUNAN CANDI SIWA MENGGUNAKAN METODE ANALISIS RESPONSE SPECTRUM DAN TIME HISTORY
}

\author{
Andina Prima Putri ${ }^{1}$ dan Reza Ranjani Yazid ${ }^{2}$ \\ ${ }^{1}$ Prodi Teknik Sipil, Jurusan Teknik Sipil dan Perencanaan, Institut Teknologi Kalimantan \\ Email: andina@lecturer.itk.ac.id \\ ${ }^{2}$ Prodi Teknik Sipil, Jurusan Teknik Sipil dan Perencanaan, Institut Teknologi Kalimantan \\ Email : rezarenzid@gmail.com
}

\begin{abstract}
ABSTRAK
Candi Siwa merupakan salah satu candi yang terdapat di kompleks Candi Prambanan yang terletak di perbatasan Yogyakarta dan Jawa Tengah. Candi Siwa mengalami kerusakan akibat gempa pada tahun 2006, setelahnya dilakukan kegiatan rehabilitasi pada Candi Siwa berupa perkuatan kolom, balok dan pelat beton bertulang. Adanya perkuatan yang diberikan pada Candi Siwa, maka perlu diketahui bagaimana kekuatan struktur tersebut apabila diberi beban gempa. Pada penelitian ini menggunakan analisis response spectrum dan analisis time history. Pembebanan yang diberikan dalam analisis mengacu pada SNI 1726:2019 dan SNI 1727:2013. Berdasarkan hasil analisis menggunakan program bantu, didapatkan nilai base shear adalah 38213,296 ton. Displacement arah X terbesar terjadi pada Undak IV sebesar 39,54 mm dan displacement terbesar arah Y terjadi pada Undak IV sebesar 25,6 $\mathrm{mm}$. Nilai drift maksimum yang terjadi pada Candi Siwa, pada arah X sebesar 0,00459 m pada Kaki I, sedangkan pada arah Y sebesar 0,00551 m terjadi pada Kaki I. Untuk level kinerja struktur Candi Siwa berdasarkan nilai drift ratio pada arah X dan arah Y masing-masing bernilai $0,0011 \mathrm{~m}$ dan 0,0007 m, nilai tersebut masuk ke dalam kategori Immediate Occupancy, yaitu kinerja yang umum digunakan dengan tingkat kerusakan yang sangat minim, risiko korban jiwa manusia yang sangat kecil, dan bangunan diharapkan mampu digunakan kembali.
\end{abstract}

Kata Kunci: drift, gempa, time history

\begin{abstract}
Siwa Temple is one of the temples in the Prambanan Temple complex which is located between Yogyakarta and Central Java. Siwa Temple was damaged by the earthquake in 2006, rehabilitation activities were carried out such as reinforced columns, beams and concrete plates. The existence of reinforcement given to the Siwa Temple it is necessary to know how the strength of the structure when given an earthquake load. In this study using response spectrum analysis and time history analysis. The loads given in the analysis refers to SNI 1726:2019 and SNI 1727:2013. Based on the analysis results, the base shear value is 38213.296 tons. The biggest $X$ direction displacement occurred at Undak IV by $39.54 \mathrm{~mm}$ and the largest displacement of $Y$ direction occurred at Undak IV by $25.6 \mathrm{~mm}$. The maximum drift value that occurs in the Siwa Temple, in the X direction of $0.00459 \mathrm{~m}$ at Foot $I$, while at the $Y$ direction of $0.00551 \mathrm{~m}$ occurs at Foot I. Performance level of the Siwa Temple based on the value of the drift ratio in the $X$ direction and $Y$ direction respectively worth $0.0011 \mathrm{~m}$ and $0.0007 \mathrm{~m}$, the value is included in the category of Immediate Occupancy, where this category is the criteria most widely used with very limited damage, the risk of fatalities due to structural failure is negligible, and the structure expected to be operated again.
\end{abstract}

Keywords: drift, earthquake, time history 


\section{PENDAHULUAN}

Bencana gempa bumi yang terjadi di Daerah Istimewa Yogyakarta pada tanggal $27 \mathrm{Mei}$ 2006 merupakan gempa bumi tektonik yang memiliki kekuatan 5,9 skala Richter. Gempa bumi tersebut menyebabkan banyak gedung dan bangunan mengalami kerusakan bahkan ada beberapa bangunan yang roboh. Kerusakan bangunan yang terjadi akibat tidak mampunya bangunan dalam menahan gaya gempa yang ada. Salah satu bangunan yang mengalami kerusakan adalah Candi Prambanan.

Kerusakan yang dialami Candi Prambanan akibat gempa pada tahun 2006 adalah kerusakan struktural dan kerusakan material dengan kondisi yang kerusakan yang bermacam-macam. Kerusakan struktural yang terjadi seperti deformasi arah vertikal dan horizontal, miring dan runtuh. Sedangkan kerusakan material yang terjadi berupa pecah, retak, patah dan mengelupas. Adanya macam-macam kerusakan ini disebabkan oleh perilaku goncangan gempa dan teknik pemugaran yang dilakukan pada zaman dahulu.

Penelitian dilakukan oleh para ahli dari tahun 2006 hingga tahun 2011 yang kemudian berlanjut pada kegiatan rehabilitasi pada tahun 2012 hingga tahun 2019. Rehabilitasi yang dilakukan pada Candi Siwa meliputi tambahan perkuatan pelat, kolom dan balok beton bertulang. Rehabilitasi dilakukan pada sebagian tubuh I, tubuh II, atap I, atap II, atap III, atap IV dan kemuncak. (Setyastuti, 2012).

Berdasarkan adanya pertambahan perkuatan yang diberikan pada Candi Siwa, maka perlu diketahui bagaimana pengaruh perkuatan tersebut terhadap kekuatan struktur dari Candi Siwa apabila diberi beban gempa. Secara umum analisis gempa dibagi menjadi dua yaitu analisis gempa statik ekivalen dan dinamik. Menurut SNI 1726:2019, pengaruh gempa rencana pada struktur dengan ketinggian lebih dari 10 tingkat atau $40 \mathrm{~m}$ harus ditinjau berdasarkan pada analisis dinamik yang terdiri terdiri dari analisis spektrum respons dan analisis dinamik riwayat waktu (time history).

Menurut Suntoko (2019), respons spektrum adalah salah satu dari analisis dinamik dimana suatu pemodelan dari struktur diberikan spektrum respons gempa rencana.

Analisis riwayat waktu adalah analisis dinamis dimana pada model struktur diberikan suatu catatan rekaman gempa. Dalam analisis ini, level kinerja yang ingin diketahui adalah level kinerja yang ditinjau berdasarkan nilai drift ratio.

Menurut ATC-40, drift ratio merupakan perbandingan antara nilai defleksi maksimum terhadap tinggi bangunan yang ditinjau. Level performa struktur dibagi menjadi sebagai berikut:

1. Immediate Occupancy (IO) yaitu kinerja yang umum digunakan dengan tingkat kerusakan yang sangat minim, risiko korban jiwa manusia yang sangat kecil, dan bangunan diharapkan mampu digunakan kembali.

2. Damage Control (DC) yaitu kinerja dengan tingkat kerusakan di antara level Immediate Occupancy sampai Life Safety.

3. Life Safety $(L S)$ yaitu kinerja dengan tingkat kerusakan signifikan pada bangunan telah terjadi, tetapi belum mencapai keruntuhan.

4. Structural Stability (SS) yaitu kinerja dengan sistem struktur bangunan yang mengalami keruntuhan sebagian atau total.

Rentang level kinerja tersebut dapat dilihat pada Tabel 1 berikut.

Tabel 1. Batasan Drift Ratio Menurut ATC-40

\begin{tabular}{ccccc}
\hline Parameter & IO & DC & LS & SS \\
\hline $\begin{array}{c}\text { Maximum } \\
\text { Drift Ratio }\end{array}$ & 0,01 & $0,01-0,02$ & 0,02 & 0,33 \\
\hline
\end{tabular}

Sumber: ATC-40 (1997)

Berdasarkan hal tersebut, penulis akan melakukan analisis gempa dinamik (respon 
spektrum dan riwayat waktu) pada Candi Siwa setelah adanya perkuatan pasca rehabilitasi dengan menggunakan program bantu, dimana analisis ini akan meninjau beberapa parameter hasil analisis seperti base shear, displacement, drift serta untuk mengetahui level kinerja struktur pada Candi Siwa yang ditinjau berdasarkan nilai drift ratio.

\section{METODE}

Data yang digunakan merupakan data struktur candi yang berupa data dimensi yang diperoleh dari BP3 - Unit Kerja Candi Prambanan oleh penelitian dari Tim Penyusunan Detail Engineering Design (DED), dan data material yang mengacu pada data Candi Garuda serta penelitianpenelitian yang telah dilakukan sebelumnya. Data ukuran dimensi dan data material Candi Siwa ditunjukkan pada Tabel 2 dan Tabel 3 berikut.

Tabel 2. Dimensi Bangunan Candi Siwa

\begin{tabular}{cccc}
\hline No. & Bagian Candi & $\begin{array}{c}\text { Tinggi } \\
\text { (cm) }\end{array}$ & $\begin{array}{c}\text { Dimensi } \\
\text { (cm) }\end{array}$ \\
\hline 1 & Fondasi & 650 & $3393 \times 3400$ \\
2 & Kaki & & \\
& a. Kaki I & 358 & $2083 \times 334$ \\
& b. Kaki II & 383 & $1068 \times 356$ \\
3 & Tubuh & & \\
& a. Tubuh I & 657,5 & $765 \times 357$ \\
& b. Tubuh II & 597,5 & $635 \times 357$ \\
4 & Atap & & \\
& a. Undak I & 432,5 & $690 \times 357$ \\
& b. Undak II & 470 & $385 \times 350$ \\
& c. Undak III & 490 & $210 \times 341$ \\
& d. Undak IV & 270 & $100 \times 332$ \\
& e. Puncak & 1020 & $115 \times 120$ \\
5 & Bilik & & \\
& a. Bilik Utama & 835 & $682 \times 682$ \\
& b. Bilik Selatan & 432 & $284 \times 282$ \\
\hline \multirow{2}{*}{. } & & &
\end{tabular}

\begin{tabular}{cccc}
\hline No. & Bagian Candi & $\begin{array}{c}\text { Tinggi } \\
\text { (cm) }\end{array}$ & $\begin{array}{c}\text { Dimensi } \\
\text { (cm) }\end{array}$ \\
\hline \multirow{2}{*}{6} & c. Bilik Barat & 438 & $285 \times 280$ \\
d. Bilik Utara & 426 & $285 \times 280$ \\
& Sungkup bilik & & \\
& a. Bilik Utama & 820 & $682 \times 682$ \\
& b. Bilik Selatan & 268 & $284 \times 282$ \\
& c. Bilik Barat & 269 & $285 \times 280$ \\
& d. Bilik Utara & 426 & $285 \times 280$ \\
\hline
\end{tabular}

Sumber: Kegiatan Studi Teknis Pelestarian Candi Siwa, Kompleks Candi Prambanan (2012)

Tabel 3. Spesifikasi Material

\begin{tabular}{|c|c|c|c|c|}
\hline $\begin{array}{c}\text { Materi } \\
\quad \text { al }\end{array}$ & $\begin{array}{c}\text { Berat } \\
\text { Jenis } \\
(\mathrm{kg} / \mathrm{m} \\
3)\end{array}$ & $\begin{array}{c}\text { Kuat } \\
\text { Teka } \\
n \\
\text { (MPa } \\
\text { ) }\end{array}$ & $\begin{array}{c}\text { Modulus } \\
\text { Elastisit } \\
\text { as (MPa) }\end{array}$ & $\begin{array}{c}\text { Poisso } \\
n \\
\text { Ratio }\end{array}$ \\
\hline Andesit & 2500 & 13 & 6000 & 0,3 \\
\hline Tuff & 1601 & 3,6 & 1345 & 0,29 \\
\hline Beton & 2330 & 22 & 19000 & 0,2 \\
\hline $\begin{array}{l}\text { Beton } \\
\text { Pengisi }\end{array}$ & 2330 & 22 & 19000 & 0,15 \\
\hline
\end{tabular}

Sumber: Kegiatan Studi Teknis Pelestarian Candi Siwa, Kompleks Candi Prambanan (2012)

\section{Pemodelan struktur}

Pemodelan struktur pada analisis kali ini, struktur dibuat lebih sederhana karena keterbatasan kemampuan program bantu. Pemodelan geometri struktur 3D dilakukan sesuai dengan dimensi yang telah diperoleh sebelumnya. Berikut pemodelan elemen Candi Siwa pada program bantu:

a. Elemen solid

Elemen solid terdiri dari batuan candi dan beton pengisi pada Candi Siwa yang dimodelkan dalam pada program bantu seperti Gambar 1 berikut. 

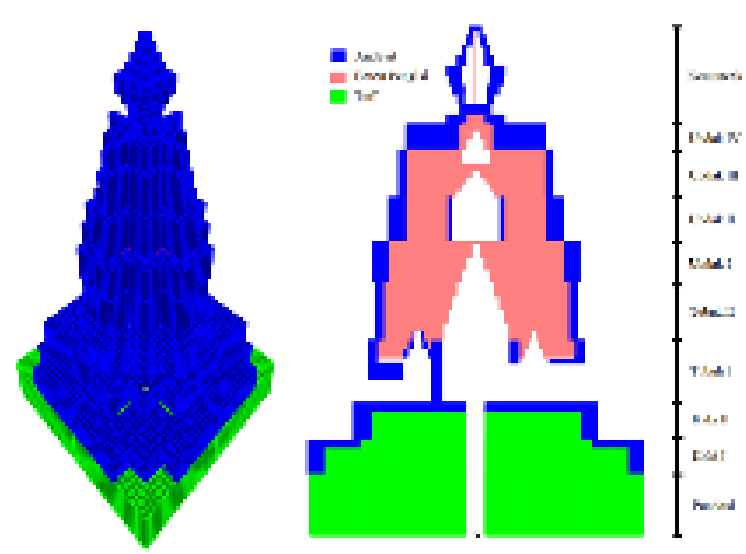

Gambar 1. Pemodelan Elemen Solid

b. Elemen frame dan area

Struktur beton dan terdiri dari balok $20 \times 20$ $\mathrm{cm}$, balok $30 \times 30 \mathrm{~cm}$ dan kolom diameter 40 $\mathrm{cm}$. struktur beton dimodelkan sebagai elemen frame pada program bantu. Pemodelan elemen Candi Siwa pada program bantu dapat dilihat pada Gambar 2, Gambar 3, dan Gambar 4 berikut.

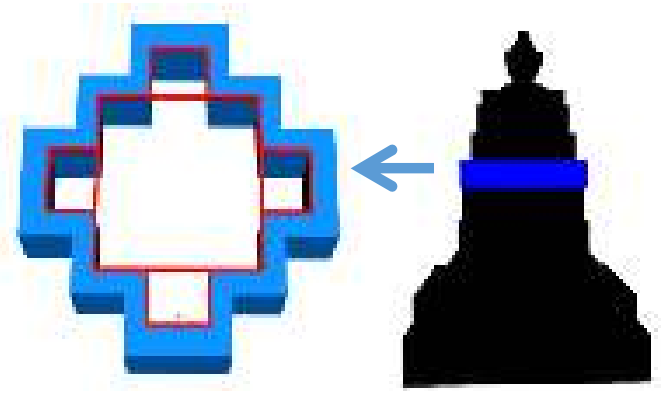

Gambar 2. Perkuatan Balok 200 x 200 mm pada Undak I

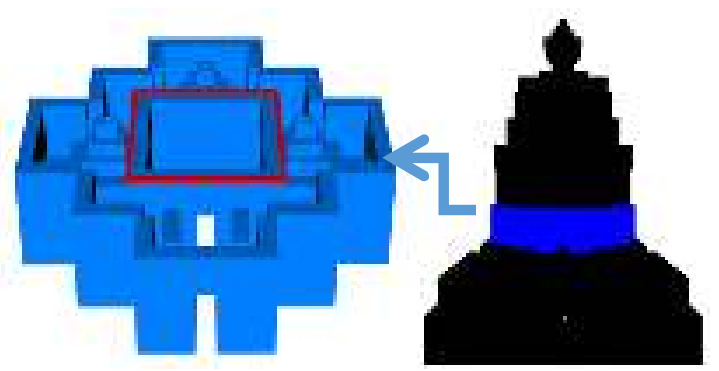

Gambar 3. Perkuatan Balok 300 x 300 mm pada Tubuh I

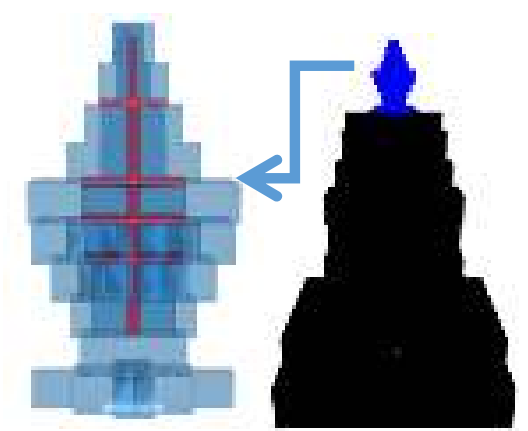

Gambar 4. Perkuatan pada Bagian Kemuncak

Struktur perkuatan berupa pelat beton yang terletak di bagian pintu masing-masing bilik dimodelkan sebagai elemen area. Bilik-bilik terletak pada bagian tubuh I candi seperti pada Gambar 5 berikut:

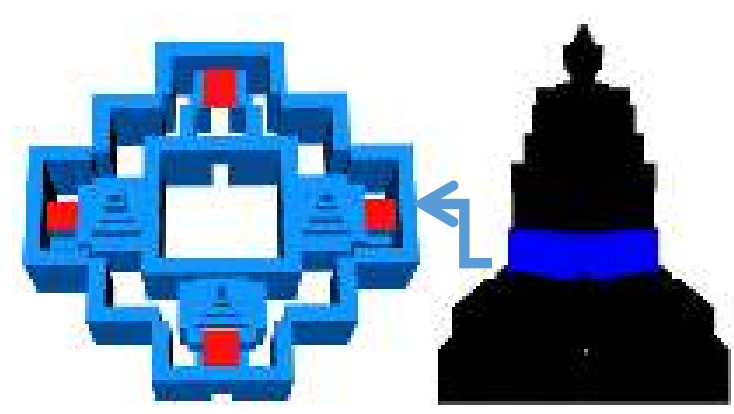

Gambar 5. Perkuatan Pelat pada Bagian Pintu Bilik

\section{c. Springs}

Pada dasar fondasi candi yang langsung berhubungan dengan tanah, dimodelkan tumpuan berupa spring dengan nilai stifness sesuai hasil uji sondir yang pernah dilakukan sebelumnya oleh Japan Center for International Cooperation dengan nilai allowable bearing capacity per unit area, $\mathrm{q}_{\mathrm{Id}}$ $=39000 \mathrm{kN} / \mathrm{m}^{2}$.

\section{Pembebanan}

Pembebanan yang diberikan pada model struktur adalah sebagai berikut:

\section{a. Beban Hidup}

Menurut SNI 1727:2013, penggunaan dari bangunan yang dianalisis akan berpengaruh pada beban hidup yang diberikan. Dalam penelitian ini, bangunan yang dianalisis 
berfungsi sebagai tempat rekreasi, maka beban hidup yang diberikan adalah sebesar $4,79 \mathrm{KN} / \mathrm{m}^{2}$.

\section{b. Beban Gempa}

Beban gempa yang digunakan adalah response spectrum berdasarkan SNI 1729:2019 dan time history dengan data accelerogram dari gempa Bengkulu yang terjadi pada 12 September 2007.

Berikut langkah-langkah melakukan analisis spektrum respons:

1. Menentukan Nilai $S_{s}$ dan $S_{1}$

2. Menentukan Nilai $F_{a}$ dan $F_{v}$

3. Perhitungan Nilai $\mathrm{S}_{\mathrm{MS}}$ dan $\mathrm{S}_{\mathrm{M} 1}$

4. Perhitungan $\mathrm{S}_{\mathrm{DS}}$ dan $\mathrm{S}_{\mathrm{D} 1}$

5. Perhitungan $\mathrm{T}_{\mathrm{S}}, \mathrm{T}_{0}$, dan $\mathrm{S}_{\mathrm{a}}$

6. Membuat grafik spektrum respons

Hasil grafik respon spektrum dimasukkan kedalam pemodelan struktur dengan mendefinisikan fungsi respon spektrum pada kotak dialog Respon Spektrum Function Definition. Pendefinisian dilakukan dengan memasukkan waktu getar alami struktur (T) dan acceleration $\left(\mathrm{S}_{\mathrm{a}}\right)$.

Berdasarkan parameter-parameter yang ada pada SNI 1729:2019 untuk response spectrum wilayah Yogyakarta adalah pada Gambar 6 berikut:

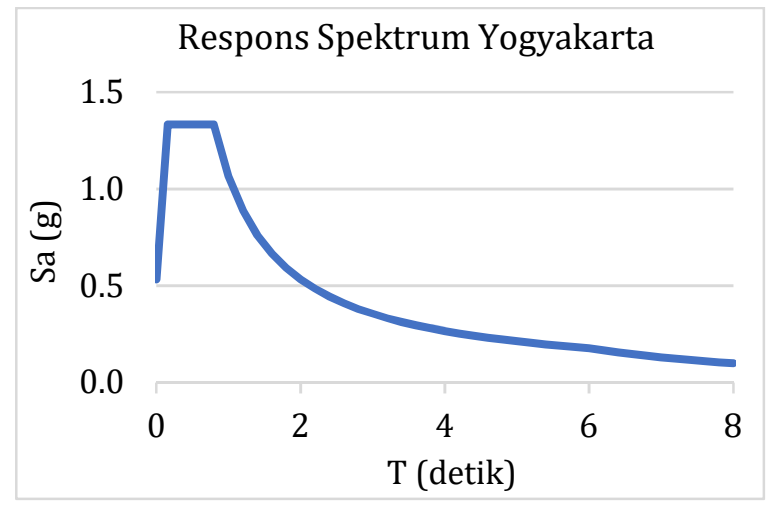

Gambar 6. Grafik Spektrum Respons Yogyakarta

Analisis time history dilakukan dengan penjelasan tahapan yaitu:
1. Memplotkan data accelerogram menjadi grafik percepatan tanah untuk masing-masing arah dari tiap stasiun.

2. Mengkonversi data accelerogram menjadi data pseudo-acceleration. Konversi data menggunakan aplikasi Seismosignal. Data yang telah di konversi diplotkan menjadi grafik pseudo-acceleration.

3. Merata-ratakan data pseudoacceleration dari masing-masing stasiun untuk arah $\mathrm{x}$ dan arah $\mathrm{y}$.

4. Menskalakan data pseudo-acceleration terhadap response spectrum acuan pada rentang $0,8 \mathrm{~T}$ hingga $1,2 \mathrm{~T}$ menggunakan faktor skala.

5. Membuat grafik dari data pseudoacceeration yang telah diskalakan terhadap respons spectrum acuan dan dicek percepatannya pada rentang $0,8 \mathrm{~T}$ hingga 1,2T tidak lebih kecil terhadap grafik response spectrum.

6. Menskalakan data accelerogram dengan menggunakan faktor skala yang sama seperti menskalakan pseudoacceleration.

7. Input data accelerogram terskala untuk masing-masing arah pada program bantu

8. Analisis time history dimulai dengan running pemodelan yang telah dilakukan pada program bantu.

9. Menganalisis perilaku struktur hasil analisis linier riwayat waktu berupa displacement, drift dan base shear.

Grafik pseudo-acceleration yang telah diskalakan terhadap response spectrum pada Gambar 7 berikut:

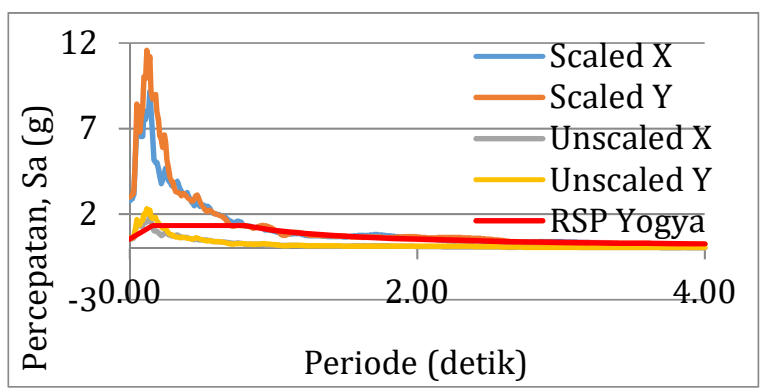

Gambar 7. Grafik Pseudo-acceleration

Terskala terhadap Response Spectrum 
Grafik pseudo-acceleration tersebut dikonversikan menjadi data accelerogram dan didapatlah beban time history untuk arah x pada Gambar 8 dan arah y pada gambar 9 berikut.

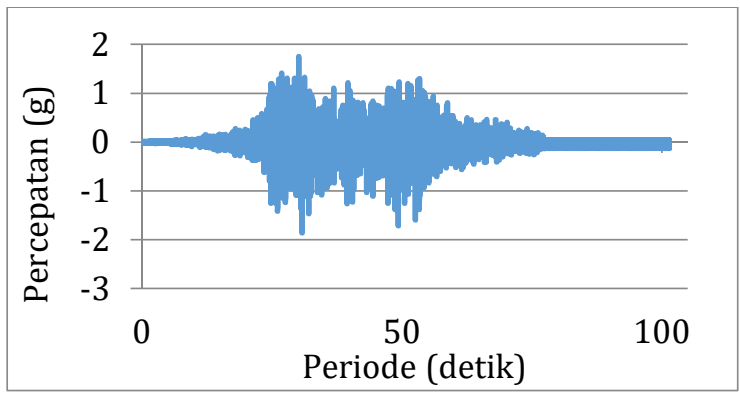

Gambar 8. Grafik Accelerogram Terskala Arah X

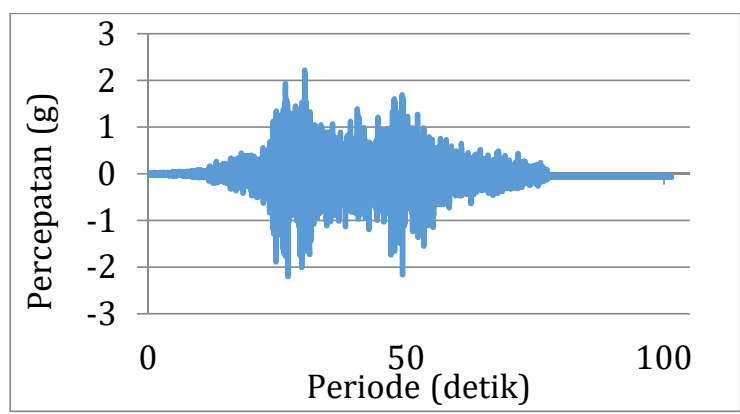

Gambar 9. Grafik Accelerogram Terskala Arah Y

\section{HASIL DAN PEMBAHASAN}

Hasil analisis yang menjadi pembahasan pada analisis time history adalah gaya geser dasar (base shear), displacement, drift dan level kinerja berdasarkan drift ratio. Berikut merupakan hasil dari analisis time history pada program bantu:

\section{a. Base shear}

Berdasarkan hasil analisis pada program bantu didapatkan nilai base shear seperti pada Tabel 4 berikut.

Tabel 4. Nilai Base Shear Maksimum

\begin{tabular}{cc}
\hline Keterangan & $\boldsymbol{V}_{\boldsymbol{t}}($ ton) \\
\hline Base Shear & 38213,296 \\
\hline
\end{tabular}

Menurut SNI 1726:2019 pasal 7.9.1.4.1, tidak lebih kecil dibanding 100\% base shear yang didapat dari cara statik ekivalen. Apabila base shear yang didapat lebih kecil, maka harus dikalikan dengan faktor skala persamaan. Hasil perhitungan kontrol terhadap base shear dapat dilihat pada Tabel 5 berikut.

Tabel 5. Kontrol Terhadap Base Shear

\begin{tabular}{ccc}
\hline \multicolumn{2}{c}{ Base Shear $(\boldsymbol{k N})$} & Keterangan \\
\hline $\boldsymbol{V}_{\boldsymbol{t}}$ & $\boldsymbol{V}$ & \\
\hline 38213,296 & 33727,375 & $V_{t}>V$ \\
\hline
\end{tabular}

\section{b. Displacement}

Dalam analisis ini, akan diambil displacement maksimum untuk dilihat bagaimana perilaku struktur ditinjau dari displacement yang diolah menjadi nilai drift. Displacement maksimum yang didapatkan dari analisis time history pada program bantu dapat dilihat pada Tabel 6 berikut:

Tabel 6. Hasil Displacement Maksimum

\begin{tabular}{ccc}
\hline Lantai & $\boldsymbol{U x}(\mathbf{m m})$ & $\boldsymbol{U y}(\mathbf{m m})$ \\
\hline Kemuncak & 39,07 & 25,36 \\
Undak 4 & 39,54 & 25,6 \\
Undak 3 & 39,06 & 25,36 \\
Undak 2 & 38,77 & 25,22 \\
Undak 1 & 38,53 & 25,08 \\
Tubuh 2 & 38,52 & 25,09 \\
Tubuh 1 & 38,51 & 25,06 \\
Kaki 2 & 36,04 & 23,85 \\
Kaki 1 & 32,77 & 22,23 \\
Pondasi & 29,33 & 26,36 \\
\hline
\end{tabular}

Berdasarkan hasil diatas, dapat dilihat bahwa displacement arah $\mathrm{x}$ terkecil terjadi pada pondasi dikarenakan dalam analisis ini pondasi dimodelkan sebagai elemen solid dengan tumpuan springs maka pondasi dapat mengalami displacement, yaitu sebesar 29,33 mm. Sedangkan, untuk 
displacement arah $\mathrm{x}$ terbesar terjadi pada Undak IV sebesar 39,54 mm. Displacement arah y terkecil terjadi pada Kaki I sebesar 22,23 mm. Sedangkan displacement maksimum arah y terjadi pada Undak IV sebesar 25,6 mm.

\section{c. Drift}

Hasil drift dihitung menggunakan persamaan pada SNI 1726:2019 Pasal 7.8.6 dengan batas simpangan antar tingkat izin yang mengacu pada persamaan Pasal 7.12.1, maka diperoleh hasil simpangan antar lantai pada Tabel 7 berikut.

Tabel 7. Rekapitulasi Perhitungan Nilai Drift

\begin{tabular}{lllll}
\hline Tingkat & $\boldsymbol{\Delta}_{\boldsymbol{x}}(\boldsymbol{m})$ & $\boldsymbol{\Delta}_{\boldsymbol{y}}(\boldsymbol{m})$ & $\begin{array}{l}\boldsymbol{\Delta}_{\boldsymbol{a}} \\
(\boldsymbol{m})\end{array}$ & Ket. \\
\hline Kemunca & 0,0006 & 0,0003 & 0,10 & Aman \\
$\mathrm{k}$ & 3 & 2 & 2 & \\
Undak 4 & 0,0006 & 0,0003 & 0,02 & Aman \\
& 4 & 2 & 7 & \\
Undak 3 & 0,0003 & 0,0001 & 0,04 & Aman \\
& 9 & 9 & 9 & \\
Undak 2 & 0,0003 & 0,0001 & 0,04 & Aman \\
& 2 & 9 & 7 & \\
Undak 1 & 0,0000 & 0,0000 & 0,04 & Aman \\
& 1 & 1 & 3 & \\
Tubuh 2 & 0,0000 & 0,0000 & 0,06 & Aman \\
& 1 & 4 & 0 & \\
Tubuh 1 & 0,0032 & 0,0016 & 0,06 & Aman \\
& 9 & 1 & 6 & \\
Kaki 2 & 0,0043 & 0,0021 & 0,03 & Aman \\
& 6 & 6 & 8 & \\
Kaki 1 & 0,0045 & 0,0055 & 0,03 & Aman \\
& 9 & 1 & 6 & \\
\hline
\end{tabular}

Berdasarkan hasil diatas, simpangan antar tingkat yang maksimum arah $\mathrm{x}$ terjadi pada Kaki I sebesar 0,00459 $\mathrm{m}$ dan simpangan antar tingkat yang maksimum arah y terjadi pada Kaki 1 sebesar 0,00551 m dengan simpangan yang diizinkan senilai $0,036 \mathrm{~m}$. Simpangan antar tingkat pada arah $\mathrm{x}$ dan arah y yang terjadi di semua tingkat masih masuk dalam yang disyaratkan SNI 1726:2019 sehingga struktur Candi Siwa dapat dikatakan aman.

\section{d. Level Kinerja Struktur}

Untuk menentukan level kinerja struktur mengacu pada ATC-40 dihitung dari maximum total drift. Berdasarkan Tabel 1, hasil level kinerja struktur dapat dilihat pada Tabel 8 berikut.

Tabel 8. Level Kinerja Struktur

\begin{tabular}{llll}
\hline Load Case & $D_{\boldsymbol{t}}(\mathbf{m m})$ & $\begin{array}{l}\text { Maximum } \\
\text { Total Drift }\end{array}$ & $\begin{array}{l}\text { Level } \\
\text { Kinerja }\end{array}$ \\
\hline Aceh X & 39,54 & 0,0011 & $I O$ \\
Aceh Y & 25,6 & 0,0007 & $I O$ \\
\hline
\end{tabular}

Berdasarkan tabel di atas diperoleh kinerja struktur Immediate Occupancy (IO) yaitu kinerja yang umum digunakan dengan tingkat kerusakan yang sangat minim, risiko korban jiwa manusia yang sangat kecil, dan bangunan diharapkan mampu digunakan kembali.

\section{KESIMPULAN}

Berdasarkan analisis yang telah dilakukan, maka dapat disimpulkan bahwa:

1. Nilai base shear yang didapat dari hasil analisis metode time history adalah 38213,296 ton. Nilai base shear metode statik ekivalen sebesar 33727,375 ton. Jadi, nilai base shear dari hasil analisis metode time history lebih besar dibanding nilai base shear metode statik ekivalen sudah sesuai dengan yang disyaratkan pada SNI Pasal 7.9.1.4.1.

2. Displacement arah $\mathrm{X}$ terbesar terjadi pada Undak IV sebesar 39,54 mm dan displacement terbesar arah $\mathrm{Y}$ terjadi pada Undak IV sebesar 25,6 mm.

3. Nilai drift maksimum yang terjadi pada Candi Siwa, pada arah $\mathrm{X}$ sebesar 0,00459 m pada Kaki I, sedangkan pada arah Y sebesar 0,00551 m terjadi pada Kaki I.

4. Berdasarkan hasil analisis, level kinerja struktur Candi Siwa berdasarkan nilai drift ratio pada arah X dan arah Y masuk ke dalam kategori Immediate Occupancy. Artinya, struktur bangunan 
aman, bangunan tidak mengalami kerusakan berarti dan bangunan dapat segera difungsikan/beroperasi kembali.

\section{DAFTAR PUSTAKA}

[1] ATC-40. (1997). Seismic Evaluation and Retrofit of Concrete Building. Applied Technology Council. California.

[2] BP3 Yogyakarta. (2009). Membangun Kembali Prambanan. Yogyakarta.

[3] SNI 1726:2019. (2019). Tata Cara Perencanaan Ketahanan Gempa Untuk Struktur Bangunan Gedung dan Non Gedung SNI 1726:2019. Badan Standarisasi Nasional. Jakarta.

[4] SNI 1727:2013. (2013). Beban Minimum Untuk Perancangan Bangunan Gedung dan Struktur Lain SNI 1727:2013. Badan Standarisasi Nasional. Jakarta.

[5] Setyastuti, A., (2012). Studi Teknis Pelestarian Candi Siwa. Kompleks Candi Prambanan. Yogyakarta.

[6] Suntoko, H., (2019). Analisis Spektrum Respon Desain Gedung Reaktor RDE Menggunakan SAP2000. Jurnal Pengembangan Energi Nuklir, Volume 21 No.1 2019. 
